Revista de Educação e Pesquisa em Contabilidade Journal of Education and Research in Accounting Revista de Educación e Investigatión en Contabilidad
REPeC, Brasília, v. 6, n. 1, art. 3, p. 38-53, jan./mar. 2012

Disponível online em www.repec.org.br ISSN 1981-8610

\title{
Análise do Grau de Cumprimento das Práticas de DivUlgaÇão Definidas pelo Pronunciamento Técnico CPC 13 no Âmbito das Companhias Abertas
}

\author{
Vera Maria Rodrigues Ponte \\ Doutora em Controladoria e Contabilidade pela USP \\ Universidade Federal do Ceará - UFC \\ Endereço: Rua Dr. Tomas Pompeu 111/1200, Meireles, CEP 60160-080, Fortaleza/Ce \\ e-mail:vponte@fortalnet.com.br
}

\section{Márcia Martins Mendes De Luca}

Doutora em Controladoria e Contabilidade pela USP

Universidade Federal do Ceará - UFC

Endereço: Rua - Cel. Jucá, 1000/1501 - Aldeota, Fortaleza/CE CEP 60.170-320

E-mail:marciadeluca@ufc.br

\author{
Marcelle Colares Oliveira \\ Doutora em Controladoria e Contabilidade pela USP \\ Universidade de Fortaleza - UNIFOR \\ Endereço: Rua Barão de Aracati, 2715/1301, Joaquim Távora - CEP 60115-082, Fortaleza/CE \\ E-mail:marcellecolares@unifor.br
}

\section{Luiz Damázio Pereira de Aquino}

Bacharel em Ciências Contábeis - UFC

Mestrando em Administração e Controladoria - UFC

Endereço: Rua Altina Maria de Jesus, 88, Horizonte/CE.

E-mail: luiazio@gmail.com

\section{Danival Sousa Cavalcante}

Mestrando em Administração e Controladoria - UFC

Especialista em Contabilidade e Planejamento Tributário - UFC

Bacharel em Ciências Contábeis - UFC

Endereço: Rua Moreira Gomes, 448, Vila União, CEP 60.410-720, Fortaleza/CE.

E-mail:danivalsc@hotmail.com

Editado em Português, Inglês e Espanhol. Versão original em Português.

Recebido em 10/12/10. Pedido de Revisão em 10/03/11. Resubmetido em 08/09/11. Aceito em 07/09/11 por Valcemiro Nossa (Editor). Publicado em 27/03/12. Organização responsável pelo periódico: CFC/FBC/ABRACICON.

Copyright (C 2012 REPEC. Todos os direitos, até mesmo de tradução, são reservados. É permitido citar parte de artigos sem autorização prévia, desde que seja identificada a fonte. 


\section{Resumo}

Com base nas Leis n ${ }^{\circ} 11.638 / 07$ e n ${ }^{\circ} 11.491 / 09$, o Comitê de Pronunciamentos Contábeis (CPC) emitiu o Pronunciamento Técnico CPC 13, visando assegurar que as primeiras demonstrações contábeis elaboradas representem um adequado ponto de partida para a Contabilidade de acordo com a nova legislação, definiu um conjunto mínimo de práticas de divulgação para adoção pelas companhias quando da publicação das demonstrações do exercício findo em dezembro de 2008. A presente pesquisa teve como principal objetivo investigar o grau de cumprimento das orientações de divulgação definidas no CPC 13 pelas companhias listadas na BM\&FBovespa e examinar se existiu uma maior observância pelas empresas dos Níveis Diferenciados de Governança Corporativa (NDGC). Este estudo descritivo investigou as notas explicativas das Demonstrações Financeiras Padronizadas publicadas do exercício encerrado em 2008 de 334 companhias (amostra). Foram utilizadas técnicas de estatística descritiva numa análise geral e realizados testes não paramétricos de diferenças entre médias, utilizando-se o modelo de Mann-Whitney para a aferição das hipóteses de pesquisa. Constatou-se um baixo grau de cumprimento das orientações de divulgação do CPC 13 pelas companhias abertas e, verificou-se que nas empresas listadas nos NDGC da BM\&FBovespa foi maior a observância do normativo, quando comparadas com as do segmento tradicional.

Palavras-chave: Disclosure; Práticas de Divulgação; Governança Corporativa.

\section{INTRODUÇÃO}

O processo de convergência das normas e práticas contábeis brasileiras aos padrões internacionais envolveu várias iniciativas, legais, institucionais e regulamentares adotadas nos últimos anos e teve como marco principal a edição da Lei $n^{\circ}$. 11.638/07, que alterou a Lei $n^{0} 6.404 / 76$. As mudanças implementadas destinam-se, principalmente, a adaptar a lei às mudanças sociais e econômicas decorrentes da evolução no ambiente de negócios e fortalecer o mercado de capitais, mediante implementação de normas contábeis e de auditoria internacionalmente reconhecidas. Espera-se que as novas práticas promovam mais transparência e qualidade das informações contábeis apresentadas pelas companhias brasileiras.

Apesar de a Lei $n^{\circ}$ 11.638/07 haver entrado em vigência em 01/01/2008, a sua efetiva implementação requereu a emissão de diversas normatizações pelo Comitê de Pronunciamentos Contábeis (CPC) ainda naquele ano. Essas regulamentações foram posteriormente aprovadas pela Comissão de Valores Mobiliários (CVM), pelo Banco Central do Brasil (Bacen), pelo Conselho Federal de Contabilidade (CFC) e por outros órgãos reguladores. Também com o objetivo de suprir questões relevantes para a adoção da Lei $\mathrm{n}^{\circ}$ 11.638/07, em 27/05/2009, passou a viger a Lei $\mathrm{n}^{\circ}$ 11.491/09 (anteriormente, Medida Provisória $n^{\circ} 449 / 08$ ), que instituiu o Regime Tributário de Transição, dentre outras providências.

Não resta dúvida que o processo de mudança em andamento é o maior já observado no mundo contábil nos últimos 30 anos, representando um grande desafio para profissionais e acadêmicos. É importante destacar que as mudanças são também culturais, razão pela qual deverá demandar algum tempo a sua plena absorção por todos os usuários das demonstrações contábeis.

Ciente dessa realidade, o CPC emitiu o Pronunciamento Técnico CPC 13 (Adoção Inicial da Lei $n^{\circ}$ 11.638/07 e da Medida Provisória $n^{\circ}$ 449/08), que tem como principal objetivo assegurar que as primeiras demonstrações contábeis elaboradas de acordo com as novas práticas contábeis adotadas no Brasil contenham informações que: a) proporcionem um adequado ponto de partida para a Contabilidade de acordo com as novas práticas contábeis adotadas no Brasil; e b) sejam transparentes e geradas a um custo que não supere os benefícios para os usuários. Levando-se em conta que muitas das alterações introduzidas na Lei $n^{\circ}$ 6.404/76 implicam mudanças de práticas contábeis que há muito vinham sendo adotadas pelas companhias, o CPC 13 definiu um conjunto mínimo de práticas de divulgação para observância já na publicação das demonstrações do exercício findo em dezembro de 2008. Vale destacar que tais orientações deveriam ter sido obrigatoriamente observadas pelas companhias abertas, uma vez que esse normativo foi aprovado pela Deliberação CVM no 565/08. 
Ressalta-se que o disclosure de informações pode se dar de forma tanto voluntária quanto compulsória, sendo que a primeira constitui uma ação proativa da entidade, geralmente advinda dos incentivos recebidos pelo administrador para divulgá-las, enquanto a segunda decorre de ação reativa, oriunda de regulamentação que obriga a empresa a divulgar determinada informação (YAMAMOTO; SALOTTI, 2006). Como destaca Welker (1995 apud MURCIA, 2009, p. 30), as companhias possuem discricionariedade na determinação do escopo, do conteúdo, do período e da forma de evidenciar informações aos usuários externos.

É possível que, mesmo havendo a obrigação da divulgação de informações acerca da adoção inicial da Lei $n^{\circ}$ 11.638/07 e da Medida Provisória n ${ }^{\circ}$ 449/08, algumas empresas não tenham cumprido as determinações do CPC devido às inúmeras dificuldades que enfrentaram na implementação das novas práticas contábeis.

Nesse contexto, a presente pesquisa procura responder ao seguinte questionamento: Qual o grau de cumprimento às orientações de divulgação do CPC 13 pelas companhias listadas na BM\&FBovespa?

Diversas pesquisas indicam haver uma ligação entre o nível de disclosure e as características de governança, sugerindo que as empresas com melhor estrutura de governança apresentariam nível mais elevado de disclosure configurando maior compromisso com a transparência e a prestação de informações fidedignas (BOTOSAN, 1997; CHEN; JAGGI, 2000; ENG; MAK, 2003; FORKER, 1992; HO; WONG, 2001, LANZANA, 2004).

Assim, adicionalmente, o presente trabalho investiga se existe relação entre a observância das orientações de divulgação do CPC 13 pelas empresas e o seu segmento de listagem na BM\&FBovespa, levando-se em conta os segmentos de níveis diferenciados de governança corporativa (NDGC) e o mercado tradicional.

Constitui, portanto, objetivo principal da pesquisa investigar o grau de cumprimento das orientações de divulgação definidas no CPC 13 pelas companhias listadas na Bolsa de Valores, Mercadorias e Futuros (BM\&FBovespa), examinando se existiu uma maior observância pelas empresas do NDGC.

Para Aguiar, Corrar e Batistella (2004, p. 338), os NDGC da BM\&FBovespa visam dar "maior transparência ao mercado de capitais como forma de atrair mais investidores e, por conseguinte, aumentar o volume de transações." Como já destacado, estudos acadêmicos (BOTOSAN, 1997; FORKER, 1992) indicam haver uma correlação entre o nível de disclosure e as características de governança apontando que as empresas com melhor estrutura de governança apresentam nível mais elevado de disclosure.

Considerando-se que muitas companhias tenham enfrentado dificuldades de adaptação às novas normas e práticas contábeis e que existe uma correlação positiva entre boa estrutura de governança e nível de disclosure, é hipótese do trabalho que nem todas as companhias observaram as orientações de divulgação do CPC 13 e nas empresas listadas nos NDGC da BM\&FBovespa foi maior a observância do normativo quando comparadas com as do segmento tradicional.

O artigo está estruturado da seguinte forma: na seção 2, apresenta-se o referencial teórico do estudo; na seção seguinte, apresentam-se os procedimentos metodológicos utilizados; a seção 4 traz a análise dos dados; e, na seção 5, apresenta-se a conclusão.

\section{REFERENCIAL TEÓRICO}

\subsection{Governança corporativa e a informação contábil}

Estudos realizados nos últimos 30 anos, a partir de pesquisas de Contabilidade na abordagem da informação (information approach) têm destacado a grande relevância da Contabilidade como fornecedora de informações para subsidiar decisões de investidores (LOPES, 2005).

O problema desta pesquisa tem seus fundamentos no conflito de agência, cujas bases conceituais têm raízes no estudo de Berle e Means (1932), assim como na assimetria da informação presente nas organizações em decorrência da separação entre a propriedade (acionistas) e a gestão (adminis- 


\section{repec}

tradores), que surge quando os agentes ligados às empresas passam a defender interesses conflitantes. Tal situação leva os acionistas a buscar informações e instrumentos de governança corporativa capazes de evitar que eles sejam expropriados pelos administradores e que propiciem o alinhamento de interesses no âmbito das empresas.

A disponibilização de informações, em resposta aos problemas da assimetria informacional, representa um dos pilares básicos da governança corporativa e está relacionada às suas próprias origens. Segundo Camargos e Helal (2007, p. 4), "historicamente, tem-se que a GC iniciou-se nos Estados Unidos sob a égide da recuperação da transparência (disclosure) e a responsabilidade de prestação de contas e monitoramento dos gestores das grandes firmas". A divulgação e transparência das informações compõem um dos seis princípios de governança corporativa estabelecidos pela Organização para a Cooperação e Desenvolvimento Econômico (OCDE) (OECD, 2009) e consta como prática recomendada em diversos códigos e cartilhas editados por outros órgãos competentes no assunto, em âmbito nacional e internacional, a exemplo do Instituto Brasileiro de Governança Corporativa IBGC (IBGC, 2009), do Fórum de Estabilização Fiscal (FEF) (FINANCIAL STABILITY FORUM, 2009), criado por representantes do G-7 (ministros da Fazenda e presidentes do Banco Central dos países-membro), e do Banco Mundial (THE WORLD BANK, 2009).

São inúmeros os estudos que associam o nível de disclosure de informações financeiras e não financeiras das empresas, obrigatórias e voluntárias, às respectivas estruturas de governança corporativa. Eng e Mak (2003) investigaram o impacto da estrutura de propriedade e da composição do conselho de administração no disclosure voluntário levando em conta a divulgação de informações estratégicas não obrigatórias, financeiras e não financeiras, e, segundo os autores, firmas de grande porte e outras com menor volume de passivo apresentam maior disclosure. Botosan (1997) investigou a associação entre o nível de divulgação voluntária de informações e o custo de capital com base no volume de informações divulgadas nos relatórios anuais de 122 empresas em 1990. Segundo o estudo de Chen e Jaggi (2000), a proporção de diretores não executivos independentes em relação ao total de diretores nos conselhos das empresas foi positivamente associada ao nível de disclosure e à qualidade de compreensão das informações, e essa associação mostrou-se fraca quando comparadas empresas de controle familiar versus controle não familiar. Ho e Wong (2001) estudaram o disclosure voluntário das empresas de Hong Kong, chegando a constatar que a existência de comitê de auditoria é positiva e significativamente relacionada com o volume e a qualidade do disclosure. Também no Brasil, diversos são os estudos que procuram entender essa associação entre nível de disclosure e características da estrutura de governança corporativa, podendo-se citar Lanzana (2004), que procurou contribuir para a discussão sobre o tema, porquanto, segundo a autora, há escassez de pesquisas acadêmicas relacionadas ao assunto no contexto brasileiro.

Na opinião de Lopes (2004), a existência de conflitos de agência e da assimetria da informação permeia a atividade das organizações modernas de forma profunda, e o papel informacional da Contabilidade ganha relevância nesse contexto. Na sua visão, "todo o sistema da Contabilidade financeira ou societária pode ser analisado à luz da redução de assimetria informacional entre investidores e agentes envoltos no conflito de agência” (LOPES, 2004, p.173). Ainda, na percepção de Lopes (2005), o mundo real opera com grandes diferenças informacionais entre os agentes e essas diferenças estão no cerne da própria existência da Contabilidade.

Ressalta-se, assim, a utilidade informacional da Contabilidade, que, variando nos ambientes legais predominantes nos diferentes países, pode ser diretamente impactada pelos mecanismos de governança corporativa, enquanto instrumentos de proteção dos investidores, em relação aos administradores e a acionistas principais, em razão tanto dos conflitos de agência quanto de problemas da assimetria de informação. Entretanto, os mecanismos de governança corporativa também variam em função de sistema legal, ambientes institucionais, aspectos culturais e históricos e nível de atuação dos mercados de capitais dos diversos países onde as empresas operam.

A globalização da economia ensejou o surgimento de demandas internacionais para a Contabilidade, cuja função informacional teve suas dimensões geográficas ampliadas. De acordo com 
Niyama (2005), a importância da Contabilidade ultrapassou as fronteiras da empresa e da economia doméstica e passou a constituir instrumento de processo decisório em âmbito internacional, principalmente no atual cenário de globalização dos mercados.

Como consequência disso, surgiu a necessidade de comparabilidade das informações produzidas pela Contabilidade em nível internacional, ou seja, do processo de harmonização contábil entre países, observando-se a mobilização de diversos organismos em prol da convergência internacional de Contabilidade. O International Accounting Standards Board (IASB) congrega representantes de mais de 140 entidades profissionais de todo o mundo, inclusive do Brasil, e tem desempenhado papel fundamental nesse processo. O objetivo do IASB de promover a convergência das normas de Contabilidade ganhou força a partir da decisão da União Europeia, mediante regulamentação aprovada em julho de 2002, obrigando todas as empresas sediadas nos seus países-membros a apresentar demonstrações contábeis consolidadas, a partir de 2005, com base nas Normas Internacionais de Contabilidade do IASB, que são as International Financial Reporting Standard (IFRS).

Estudos abordam as vantagens, os benefícios e as consequências da adoção das IFRS. O estudo de Christensen, Lee e Walker (2007) analisa as consequências econômicas para as empresas do Reino Unido a partir da decisão da União Europeia de impor as IFRS como obrigatórias. Os resultados empíricos apontaram evidências de que os preços de ações de empresas do Reino Unido reagiram positivamente à adoção obrigatória das IFRS.

O estudo de Cortesi, Montani e Tettamanzi (2009) centra-se nas empresas listadas na Bolsa de Milão e em suas demonstrações financeiras consolidadas, que, a partir do exercício de 2005, deveriam ser publicadas de acordo com as normas internacionais de Contabilidade. O objetivo do estudo foi identificar os principais impactos da passagem do sistema de Contabilidade italiano para o sistema de Contabilidade internacional sobre os mais importantes itens da demonstração financeira (Lucro Líquido). Os resultados provenientes de evidências empíricas possibilitaram constatar que o impacto global sobre o Lucro Líquido foi positivo, graças à aplicação de diferentes taxas de depreciação para diferentes ativos quando a taxa de depreciação era menor do que a anteriormente praticada, ocorrendo redução nas despesas, com reflexo positivo no lucro.

Conforme Leite (2002), a globalização dos mercados, no que tange ao desenvolvimento do mercado de capitais internacional, ao crescimento dos investimentos diretos estrangeiros e à formação de blocos econômicos, traz consigo a necessidade de um conjunto de normas contábeis internacionais que viabilizem a comparação de informações entre companhias.

Segundo Niyama (2005), a convergência leva em conta os diferentes ambientes institucionais, legais e de governança corporativa entre os países, e não significa uma padronização, mas uma harmonização que, enquanto procura preservar as particularidades inerentes a cada país, possibilita reconciliar os sistemas contábeis com outros países de modo a melhorar o intercâmbio de informações, bem como sua interpretação e compreensão.

\subsection{A convergência contábil no Brasil: a Lei no 11.638/07, a Lei no 11.491/09 e o CPC 13}

O processo de harmonização contábil brasileiro começou a ser discutido na década de 1990 e motivou a criação, pela CVM, da Comissão Consultiva para Assuntos Contábeis que elaborou o primeiro Anteprojeto de revisão da Lei ${ }^{\circ}$ 6.404/76, em seguida convertido no Projeto de Lei $n^{\circ}$ 3.741/2000 (MELLO; CIA; 2007; GERON, 2008). Proposto pela CVM, o mencionado Anteprojeto tinha como finalidade modernizar e harmonizar as disposições da lei societária vigente com os princípios fundamentais e as melhores práticas contábeis internacionais.

A demora da aprovação do citado Projeto de Lei, que previa a criação de uma entidade com a finalidade de estudar e divulgar princípios, normas e padrões de Contabilidade e auditoria, levou o CFC, por meio da Resolução CFC n ${ }^{\circ} 1.055$, de 07/10/2005, a criar o Comitê de Pronunciamentos Contábeis (CPC), que, segundo o art. $3^{\circ}$ da referida Resolução, tem por objetivo: 


\section{repec}

O estudo, o preparo e a emissão de Pronunciamentos Técnicos sobre procedimentos de Contabilidade e a divulgação de informações dessa natureza, para permitir a emissão de normas pela entidade reguladora brasileira, visando à centralização e uniformização do seu processo de produção, levando sempre em conta a convergência da Contabilidade Brasileira aos padrões internacionais.

Em 2007, a promulgação da Lei $\mathrm{n}^{\circ} 11.6387$ alterou principalmente os dispositivos contábeis da Lei $\mathrm{n}^{\circ} 6.404 / 76$, adaptando a Contabilidade nacional aos princípios que norteiam o padrão internacional (GERON, 2008). Segundo Geron (2008), a maior mudança oriunda da Lei $n^{\circ} 11.638 / 2007$ foi a introdução da nova filosofia contábil, abrangendo a primazia da essência econômica sobre a forma, a primazia da análise dos riscos e benefícios sobre a propriedade jurídica e a adoção de normas orientadas em princípios e julgamentos. A Lei não menciona expressamente tal mudança, mas determina que a normatização contábil seja feita de forma convergente às normas internacionais que adotam essa filosofia.

Além dessa mudança, ressaltam-se outras alterações oriundas da Lei $n^{0} 11.638 / 2007$, como: a) a criação do grupo de intangível composto pelos bens incorpóreos; b) a inclusão do conceito de fair value ou valor justo na avaliação de ativos e passivos, sob a denominação de valor de mercado ou equivalente; c) a introdução da conta Ajuste de Avaliação Patrimonial, para receber aumentos ou reduções de ativos e de passivos, em decorrência de suas avaliações a preços de mercado; d) a inclusão do teste de impairment ou teste de redução ao valor recuperável de ativos; e) a proibição de registro das doações e subvenções para investimento na conta de Reserva de Capital, devendo agora transitar pelo resultado do exercício; f) a proibição de constituição de novas reservas de reavaliação, cujos saldos devem ser estornados ou preservados até sua realização; g) a substituição da Demonstração das Origens e Aplicação de Recursos (DOAR) pela Demonstração dos Fluxos de Caixa (DFC); e h) a obrigatoriedade de publicação da Demonstração do Valor Adicionado (DVA) por parte das companhias abertas.

Em decorrência da promulgação da Lei no 11.638/07, em 2008, o CPC emitiu diversos pronunciamentos contábeis com aplicação voltada para o encerramento das demonstrações contábeis referentes ao exercício findo em 31 de dezembro daquele ano. Como forma de resolver questões que impediam a plena aplicação das novas práticas contábeis, foi editada a Lei no 11.941/09. Além de introduzir o Regime Tributário Transitório, a citada lei promoveu diversas alterações na Lei $n^{0}$ 6.404/76 visando a convergência às práticas contábeis internacionais, como: a) a modificação da nomenclatura dos grupos de contas do Ativo e do Passivo, os quais foram subdivididos em: Circulante e não circulante; b) a eliminação da terminologia Não Operacional na Demonstração do Resultado do Exercício (DRE); c) a eliminação do Ativo Diferido; d) a eliminação do grupo Resultado de Exercícios Futuros; e e) a mudança de denominação do termo de Valor de Mercado para Valor Justo.

Ciente de que as mudanças introduzidas pelas leis $\mathrm{n}^{\mathrm{o}}$ 11.638/07 e $\mathrm{n}^{\mathrm{o}}$ 11.941/09 geram relevantes impactos sobre o patrimônio líquido e o resultado das companhias, o CPC emitiu o Pronunciamento Técnico CPC 13 (Adoção Inicial da Lei no 11.638/07 e da Medida Provisória no 449/08) visando garantir que as primeiras demonstrações contábeis elaboradas representem um adequado ponto de partida para a Contabilidade, de acordo com as novas práticas contábeis adotadas no Brasil. O CPC 13 teve como principal objetivo especificar orientações para as mensurações, registros e divulgações contábeis, no primeiro ano da aplicação das leis no 11.638/07 e no 11.941/09, ou seja, o documento atua como um guia para facilitar a adoção dessas novidades.

As exigências de ajustes trazidos pelas leis $n^{0} 11.638 / 07$ e $n^{0}$ 11.941/09 não se enquadram como mudanças de circunstâncias, estimativas ou evento econômico subsequente, porquanto decorrem de processo normativo em direção às normas internacionais de Contabilidade. Assim, os ajustes deveriam ser contabilizados de acordo com as disposições contábeis aplicáveis à mudança de prática contábil adotando-se a norma "Práticas Contábeis, Mudanças nas Estimativas Contábeis e Correção de Erros". Todavia, levando-se em conta os custos envolvidos na plena aplicação desse normativo e as dificuldades que muitas empresas poderiam vir a enfrentar, o CPC 13 desobriga as entidades no tocante à aplicação dessa nor- 
ma, devendo ser observado apenas o que preceitua o $\S 1^{\circ}$. do art. 186 da Lei $n^{\circ} 6.404 / 76$, segundo o qual os correspondentes ajustes iniciais serão contabilizados na conta de Lucros ou Prejuízos Acumulados.

Como regra geral, o CPC 13 requer que a entidade cumpra as determinações das leis $n^{\circ}$ 11.638/07 e $n^{\circ} 11.941 / 09$ para encerramento de suas primeiras demonstrações contábeis sob a vigência da nova legislação. Permite, contudo, dispensas em situações específicas nas quais o custo de sua observância supere os benefícios aos usuários das demonstrações contábeis, ou ainda, em áreas em que seja impraticável a aplicação das exigências. O CPC 13 também oferece alternativas de mensuração e registro de eventos contábeis complexos, facultando às entidades a escolha mais adequada em cada caso específico. A seguir, são apresentadas as principais situações nas quais as companhias devem fazer a seleção de práticas.

De acordo com o CPC 13, a empresa deve eleger a data de transição, que corresponde ao momento em que as novas práticas passarão a ser adotadas, podendo optar entre seguir o teor do $\S 1^{\circ}$ do art. 186 da Lei ${ }^{\circ} 6.404 / 76$ adotando como data de transição o dia $1^{\circ}$ de janeiro de 2008 ou observar a NBC T 19.11, definindo como data de transição o dia $1^{\circ}$ de janeiro de 2007.

As novas regras de classificação dos instrumentos financeiros podem ser aplicadas a partir da data da transação original ou, alternativamente, na data de transição.

Os saldos existentes no Ativo Diferido, extinto pela Lei $n^{\circ} 11.941 / 09$, podem ser reclassificados ou baixados na data de transição, ou ainda permanecer nesse grupo até sua completa amortização.

Segundo as novas práticas contábeis, os elementos integrantes do Ativo e do Passivo decorrentes de operações de longo prazo ou de curto prazo, quando relevantes, devem ser ajustados a valor presente. $\mathrm{O}$ cálculo do ajuste a valor presente deve ser efetuado para todos os saldos em aberto com base em cálculo global, ou, opcionalmente, de forma individualizada para cada grupo de contas. No cálculo do ajuste a valor presente, a empresa deve optar entre a taxa de desconto com base nas condições da data da transação e a taxa de desconto com base nas condições da data de transição.

As Leis no 11.638/07 e n $n^{0}$ 11.941/09 alteraram o conceito de coligada e o alcance da aplicação do método da equivalência patrimonial. Os investimentos que antes eram avaliados pelo método do custo e passaram a ser avaliados pela equivalência patrimonial podem ser ajustados contra a conta Lucros ou Prejuízos Acumulados, ou, se preferir, a empresa pode fazer retroagir o cálculo da equivalência, apurando ágio ou deságio gerado na data original do investimento.

Ficou proibida a constituição de novas reservas de reavaliação, devendo os saldos existentes ser mantidos até sua efetiva realização ou estornados até o término do exercício social de 2008.

A DFC e a DVA, que passaram a ser obrigatórias pela nova legislação, podem ser publicadas de forma comparativa ou não.

Observa-se que, dada a complexidade das mudanças contábeis e as situações de dispensa e escolha previstas no CPC 13, a comparabilidade e a transparência das demonstrações contábeis de 2008 podem ser bastante prejudicadas, caso as companhias não adotem boas práticas de divulgação, no sentido de garantir o entendimento de suas demonstrações contábeis pelos usuários externos.

Dada a relevância dessa questão, o CPC 13 dedica especial atenção à definição de um conjunto mínimo de divulgações a ser observado pelas entidades. A exigência primeira é que as empresas afirmem, explicitamente e sem ressalvas, o cumprimento integral da referida Lei por meio de declaração na nota explicativa que descreve a apresentação das demonstrações e/ou a seleção das práticas contábeis. É requerido também:

(a) Declaração, em nota explicativa da base de elaboração e apresentação das demonstrações contábeis, de que está adotando pela primeira vez a Lei no . 11.638/07 e Medida Provisória $n^{\circ} 449 / 08$.

(b) Apresentação do sumário das práticas contábeis modificadas, acompanhado de demonstração dos efeitos no resultado e no patrimônio líquido da adoção inicial da Lei no. 11.638/07 e Medida Provisória no 449/08, com a finalidade de suprir informações quanto à comparabilidade do resultado e do patrimônio líquido com os valores que 
seriam obtidos caso não tivessem existido essas modificações. Com isso fica dispensada a divulgação do balanço inicial ajustado.

(c) Divulgação, em notas explicativas, das opções relevantes efetuadas pela administração, previstas ao longo deste Pronunciamento (CPC 13, 2008).

Dentre as divulgações elencadas, merece destaque a apresentação do sumário das práticas contábeis modificadas, indispensável para o bom entendimento das modificações no patrimônio líquido e no resultado da companhia. O Quadro 1 relaciona as práticas de divulgação definidas no CPC 13.

\begin{tabular}{|l|}
\hline \multicolumn{1}{|c|}{ Práticas de Divulgação } \\
\hline Declarar em nota explicativa o cumprimento integral da Lei no $11.638 / 07$ \\
\hline Declarar em nota explicativa que está adotando pela primeira vez as determinações da Lei n ${ }^{\circ}$ 11.638/07 e da MP449/08 \\
\hline Apresentar sumário das práticas modificadas pela companhia \\
\hline Apresentar demonstração dos efeitos das novas práticas contábeis no resultado de 2008 \\
\hline Apresentar demonstração dos efeitos da adoção inicial da Lei n ${ }^{\circ} 11.638 / 07$ e MP 449/08 no patrimônio líquido \\
\hline Divulgar, em notas explicativas, as opções relevantes feitas pela administração, dentre aquelas previstas no CPC 13 \\
\hline
\end{tabular}

Quadro 1- Práticas de divulgação definidas pelo CPC 13.

\section{METODOLOGIA}

Com o objetivo principal de investigar o grau de cumprimento das orientações de divulgação definidas no CPC 13, foram tomadas as Demonstrações Financeiras Padronizadas (DFP) de 2008 publicadas pelas empresas listadas na BM\&FBovepsa e disponibilizadas na base de dados da CVM até a data de 30/09/2009. Foram excluídas as instituições financeiras e afins (83 empresas) e companhias cujos dados não estavam disponíveis no portal eletrônico da CVM (16 empresas). Assim, de um total de 433 empresas com demonstrações registradas no portal eletrônico da CVM, foram analisadas as DFPs de 334 companhias, sendo 199 do mercado tradicional (MT), 93 do Novo Mercado (NM), 27 do Nível 1 (N1) e 15 do Nível 2 (N2).

Os dados referentes às práticas de divulgação adotadas pelas companhias foram coletados das notas explicativas (NE) das DFPs, investigando-se principalmente aquela que tratava da adoção inicial da Lei $n^{\circ}$ 11.638/07 e da MP 449/08 (convertida na Lei $n^{\circ} 11.941 / 09$ ). A leitura das NEs possibilitou identificar o grau de cumprimento das empresas a cada uma das seis determinações obrigatórias definidas pelo CPC 13, apresentadas no Quadro 1. Para cada uma das seis divulgações obrigatórias foi criada uma variável dicotômica que recebeu o valor 1 (quando a empresa aderiu à determinação) ou o valor 0 (quando a empresa não aderiu à determinação).

Foi criada a variável Nota de Divulgação, resultante da soma dos valores atribuídos às variáveis relacionadas com grau de cumprimento às divulgações obrigatórias. Assim, a variável Nota de Divulgação de cada empresa recebeu um valor inteiro entre 0 e 6 . $O$ valor 0 indicou que a empresa não aderiu a nenhuma das divulgações obrigatórias, enquanto a nota 6 apontou que a empresa aderiu a todas as determinações do CPC 13.

Também foram levantados o segmento de listagem das empresas, mediante consulta ao portal eletrônico da BM\&FBovespa na posição de 30/09/2009. Todos os dados foram registrados em planilha Excel para posterior análise com auxílio do SPSS.

Após a completa tabulação dos dados, foram calculadas medidas estatísticas como média, mediana, moda, variância e desvio-padrão, as quais possibilitaram uma análise geral acerca do cumprimento das empresas às determinações de divulgação do CPC 13. Esses modelos estatísticos simples foram utilizados também para comparar as Notas de Divulgação obtidas pelas empresas do mercado tradicional com as das empresas dos demais segmentos de listagem. 
Pesquisas geralmente relacionam a divulgação de informações pelas empresas com a existência de incentivos econômicos, valendo destacar os estudos de Lima (2007), Murcia e Santos (2009) e Lanzana (2004). Pereira et al (2008) observaram uma associação positiva entre o nível de disclosure e a adesão a um dos níveis diferenciados de governança corporativa da BM\&FBovespa. $\mathrm{O}$ estudo de Costa, Goldner e Galdi (2007) indica que a participação nos níveis diferenciados de governança corporativa da BM\&FBovespa influencia o disclosure dos maiores bancos brasileiros.

Assim, apoiado nos resultados de pesquisas anteriores, foram definidas as seguintes hipóteses a serem testadas:

H1: As Notas de Divulgação das empresas dos níveis diferenciados de governança corporativa $\left(\mathrm{ND}_{\mathrm{NDGC}}\right)$ são superiores às Notas de Divulgação das empresas do mercado tradicional $\left(\mathrm{ND}_{\mathrm{MT}}\right)$ :

H2: As Notas de Divulgação das empresas do Nível $1\left(\mathrm{ND}_{\mathrm{N} 1}\right)$ são superiores às Notas de Divulgação das empresas do mercado tradicional $\left(\mathrm{ND}_{\mathrm{MT}}\right)$ :

H3: As Notas de Divulgação das empresas do Nível $2\left(\mathrm{ND}_{\mathrm{N} 2}\right)$ são superiores às Notas de Divulgação das empresas do mercado tradicional $\left(\mathrm{ND}_{\mathrm{MT}}\right)$ :

H4: As Notas de Divulgação das empresas do Novo Mercado $\left(\mathrm{ND}_{\mathrm{NM}}\right)$ são superiores às Notas de Divulgação das empresas do mercado tradicional $\left(\mathrm{ND}_{\mathrm{MT}}\right)$ :

Para aferição das hipóteses, foram realizados testes não paramétricos de diferenças entre médias, utilizando-se o modelo de Mann-Whitney. O teste não paramétrico de Mann-Whitney pode ser usado quando existem participantes diferentes em cada condição; a aplicação do teste de médias é interessante, pois avalia se existe diferença significativa entre as médias em cada condição (DANCEY, REIDY, 2006). Ressalta-se que o teste de Mann-Whitney, diferentemente do teste $\mathrm{t}$ (Student), não tem como premissa básica a normalidade da distribuição dos dados, ou seja, para efetuar o teste de Mann-Whitney a distribuição não precisa ser obrigatoriamente normal. Dessa forma, não foram realizados testes paramétricos $\mathrm{t}$ (Student), porque a aplicação do teste Kolmogorov-Smirnov revelou que os dados das amostras não apresentavam distribuição normal.

\section{ANÁLISE DOS RESULTADOS}

\subsection{Compliance com as determinações do CPC 13}

Como forma de garantir a transparência e comparabilidade mínima entre as informações financeiras de 2007 e as de 2008, o CPC 13 definiu um conjunto de seis divulgações que deveriam ser necessariamente observadas pelas companhias abertas quando da adoção inicial da Lei $\mathrm{n}^{\mathrm{o}}$ 11.638/07 e da MP 449/08 (convertida na Lei no 11.941/09), conforme apresentado no Quadro 1.

A Tabela 1 apresenta o grau de cumprimento das empresas pesquisadas no que tange às divulgações obrigatórias definidas no CPC 13.

Verifica-se um baixo grau de cumprimento das orientações de divulgação do CPC 13 pelas companhias abertas. Apenas 33, ou seja, menos de $10 \%$ da amostra, declararam explicitamente o cumprimento integral do teor da Lei $\mathrm{n}^{\mathrm{o}}$ 11.638/07. A apresentação da demonstração dos efeitos das novas normas contábeis no resultado e no PL também foi negligenciada, sendo feita por apenas $47 \%$ das empresas. A evidenciação do sumário das práticas modificadas e das opções relevantes adotadas revelou maiores frequências, porém ainda insuficientes, já que esses dois itens, ainda que indispensáveis para o entendimento das demonstrações, deixaram de ser divulgados por 59 e 110 empresas, respectivamente. Vale mencionar também que a apresentação dos efeitos das novas práticas no resultado de 2008 e da adoção inicial da Lei n ${ }^{\circ}$ 11.638/07 e MP 449/08 no patrimônio líquido foi implementada por menos da metade do total de companhias pesquisadas. 
Tabela 1- Compliance com as práticas de divulgação definidas no CPC 13

\begin{tabular}{l|c|c|c}
\hline \multicolumn{1}{c|}{ Práticas de Divulgação } & Sim & \% & Não \\
\hline Declarar em nota explicativa o cumprimento integral do teor da Lei $\mathrm{n}^{\circ} 11.638 / 07$ & 33 & $9,9 \%$ & 301 \\
\hline $\begin{array}{l}\text { Declarar em nota explicativa que está adotando pela primeira vez as determinações da Lei } \mathrm{n}^{\circ} \\
11.638 / 07 \text { e da MP 449/08 }\end{array}$ & 131 & $39,2 \%$ & 203 \\
\hline Apresentar sumário das práticas modificadas pela companhia & 275 & $82,3 \%$ & 59 \\
\hline Apresentar demonstração dos efeitos das novas práticas contábeis no resultado de 2008 & 149 & $44,6 \%$ & 185 \\
\hline $\begin{array}{l}\text { Apresentar demonstração dos efeitos da adoção inicial da Lei } \mathrm{n}^{\circ} 11.638 \text { e da MP 449/08 no } \\
\text { patrimônio líquido }\end{array}$ & 157 & $47,0 \%$ & 177 \\
\hline $\begin{array}{l}\text { Divulgar, em notas explicativas, as opções relevantes feitas pela administração, dentre } \\
\text { aquelas previstas no CPC 13 }\end{array}$ & 224 & $67,1 \%$ & 110 \\
\hline
\end{tabular}

Nesse cenário, é possível que analistas do mercado de capitais e demais usuários das demonstrações hajam enfrentado dificuldades na análise dos resultados e das mutações ocorridas nos patrimônios líquidos das companhias.

Analisando-se o grau de compliance por segmento de listagem da BM\&FBovespa, é possível observar uma maior proporção das empresas dos segmentos diferenciados no tocante à observância das determinações do CPC 13 (Tabela 2). Com efeito, enquanto 65,6\% das empresas do Novo Mercado apresentaram os efeitos das práticas contábeis modificadas no resultado de 2008, apenas 34,2\% das companhias do mercado tradicional adotaram a prática. Situação semelhante ocorreu com o item relacionado à evidenciação dos efeitos no PL, implementado por $71 \%$ das empresas do Novo Mercado e por apenas $32,7 \%$ daquelas atuantes no mercado tradicional.

Tabela 2 - Compliance com as práticas de divulgação definidas no CPC 13 por segmento da BM\&FBovespa

\begin{tabular}{|c|c|c|c|c|c|c|c|c|c|c|c|c|}
\hline \multirow{2}{*}{ Práticas de Divulgação } & \multicolumn{3}{|c|}{ MT } & \multicolumn{3}{|c|}{ N1 } & \multicolumn{3}{|c|}{ N2 } & \multicolumn{3}{|c|}{ NM } \\
\hline & Sim & $\%$ & Não & Sim & $\%$ & Não & Sim & $\%$ & Não & Sim & $\%$ & Não \\
\hline $\begin{array}{l}\text { Declarar em nota explicativa } \\
\text { o cumprimento integral do } \\
\text { teor da Lei } n^{\circ} 11.638 / 07\end{array}$ & 14 & $7,0 \%$ & 185 & 8 & $29,6 \%$ & 19 & 3 & $20,0 \%$ & 12 & 8 & $8,6 \%$ & 85 \\
\hline $\begin{array}{l}\text { Declarar em nota explicativa } \\
\text { que está adotando pela primei- } \\
\text { ra vez as determinações da Lei } \\
\mathrm{n}^{\circ} 11.638 / 07 \text { e da MP } 449 / 08\end{array}$ & 75 & $37,7 \%$ & 124 & 8 & $29,6 \%$ & 19 & 4 & $26,7 \%$ & 11 & 44 & $47,3 \%$ & 49 \\
\hline $\begin{array}{l}\text { Apresentar sumário das prá- } \\
\text { ticas modificadas pela com- } \\
\text { panhia }\end{array}$ & 147 & $73,9 \%$ & 52 & 25 & $92,6 \%$ & 2 & 15 & $100,0 \%$ & 0 & 88 & $94,6 \%$ & 5 \\
\hline $\begin{array}{l}\text { Apresentar demonstração dos } \\
\text { efeitos das novas práticas con- } \\
\text { tábeis no resultado de } 2008\end{array}$ & 68 & $34,2 \%$ & 131 & 12 & $44,4 \%$ & 15 & 8 & $53,3 \%$ & 7 & 61 & $65,6 \%$ & 32 \\
\hline $\begin{array}{l}\text { Apresentar demonstração } \\
\text { dos efeitos da adoção inicial } \\
\text { da Lei n }{ }^{\circ} 11.638 \text { e da MP } 449 \\
\text { no patrimônio líquido }\end{array}$ & 65 & $32,7 \%$ & 134 & 17 & $63,0 \%$ & 10 & 9 & $60,0 \%$ & 6 & 66 & $71,0 \%$ & 27 \\
\hline $\begin{array}{l}\text { Divulgar, em notas explicati- } \\
\text { vas, as opções relevantes fei- } \\
\text { tas pela administração, dentre } \\
\text { aquelas previstas no CPC } 13\end{array}$ & 111 & $55,8 \%$ & 88 & 21 & $77,8 \%$ & 6 & 11 & $73,3 \%$ & 4 & 81 & $87,1 \%$ & 12 \\
\hline
\end{tabular}


Conforme explicitado na seção Metodologia, foi criada uma variável Nota de Divulgação que procurou sintetizar o grau de cumprimento das determinações de divulgação pelas companhias. Cada empresa recebeu uma nota variando de 1 a 6 em função dos itens de evidenciação publicados. As notas das empresas da amostra são explicitadas na Tabela 3.

Tabela 3 - Notas de divulgação por segmento da BM\&FBovespa

\begin{tabular}{c|c|c|c|c|c|c|c|c}
\hline \multirow{2}{*}{ Segmento } & \multicolumn{7}{|c|}{ Nota de Divulgação } & \multirow{2}{*}{ Total } \\
\cline { 2 - 8 } & $\mathbf{0}$ & $\mathbf{1}$ & $\mathbf{2}$ & $\mathbf{3}$ & $\mathbf{4}$ & $\mathbf{5}$ & $\mathbf{6}$ & \\
\hline MT & 24 & 39 & 51 & 24 & 38 & 23 & 0 & 199 \\
\hline N1 & 0 & 3 & 5 & 6 & 6 & 6 & 1 & 27 \\
\hline N2 & 0 & 1 & 1 & 7 & 4 & 2 & 0 & 15 \\
\hline NM & 2 & 1 & 12 & 18 & 32 & 27 & 1 & 93 \\
\hline Total & $\mathbf{2 6}$ & $\mathbf{4 4}$ & $\mathbf{6 9}$ & $\mathbf{5 5}$ & $\mathbf{8 0}$ & $\mathbf{5 8}$ & $\mathbf{2}$ & $\mathbf{3 3 4}$ \\
\hline
\end{tabular}

Chama atenção empresas de o Novo Mercado terem obtido nota zero, significando que nenhuma das divulgações exigidas foi cumprida por referidas companhias. Também não se esperava que empresas dos Níveis Diferenciados da BM\&FBovespa alcançassem apenas a nota 1 (um), totalizando cinco delas, sendo três do Nível 1, uma do Nível 2 e uma do Novo Mercado. Três dessas empresas se limitaram a apresentar o sumário das práticas modificadas; enquanto uma delas demonstrou os efeitos das mudanças no patrimônio líquido e a outra evidenciou suas opções relevantes.

A análise dos dados da Tabela 3 revela também uma concentração das notas das empresas do mercado tradicional no intervalo de 0 a 2 , enquanto as demais obtiveram notas entre 3 e 6 . A Tabela 4 apresenta a frequência acumulada das notas por segmento elucidando melhor essa questão.

Tabela 4 - Frequência acumulada das notas de divulgação por segmento

\begin{tabular}{c|c|c|c|c|c|c|c|c}
\hline \multirow{2}{*}{$\begin{array}{c}\text { Nota de } \\
\text { Evidenciação }\end{array}$} & \multicolumn{2}{|c|}{ Mercad Tradicional } & \multicolumn{2}{c|}{ Nível 1 } & \multicolumn{2}{c|}{ Nível 2 } & \multicolumn{2}{c}{ Novo Mercado } \\
\cline { 2 - 10 } & Freq. & $\begin{array}{c}\text { \% } \\
\text { Acumulado }\end{array}$ & Freq. & $\begin{array}{c}\text { \% } \\
\text { Acumulado }\end{array}$ & Freq. & $\begin{array}{c}\text { \% } \\
\text { Acumulado }\end{array}$ & $\begin{array}{c}\text { Freq. } \\
\text { Acumulado }\end{array}$ \\
\hline 0 & 24 & 12,10 & 0 & 0,00 & 0 & 0,00 & 2 & 2,15 \\
\hline 1 & 39 & 31,70 & 3 & 11,10 & 1 & 6,70 & 1 & 3,23 \\
\hline 2 & 51 & 57,30 & 5 & 29,60 & 1 & 13,30 & 12 & 16,13 \\
\hline 3 & 24 & 69,30 & 6 & 51,90 & 7 & 60,00 & 18 & 35,48 \\
\hline 4 & 38 & 88,40 & 6 & 74,10 & 4 & 86,70 & 32 & 69,89 \\
\hline 5 & 23 & 100,00 & 6 & 96,30 & 2 & 100,00 & 27 & 98,92 \\
\hline 6 & & & 1 & 100,00 & & & 1 & 100,00 \\
\hline Total & $\mathbf{1 9 9}$ & - & $\mathbf{2 7}$ & - & $\mathbf{1 5}$ & - & $\mathbf{9 3}$ & - \\
\hline
\end{tabular}

Observa-se que $57,3 \%$ das empresas do mercado tradicional obtiveram notas entre 0 e 2 . Por seu turno, apenas 29,6\%,13,3\% e 16,1\% das empresas do Nível 1, do Nível 2 e do Novo Mercado, respectivamente, apresentaram situação semelhante.

A Tabela 5 apresenta a estatística descritiva envolvendo a variável Nota de Divulgação. Observa-se que o grupo das empresas do mercado tradicional apresentou os menores valores para as medidas de tendência central. Com efeito, enquanto as notas das empresas desse segmento registram média 2,41, as dos demais grupos revelam desempenho superior a 3, sendo 3,37 para as empresas do Nível 1; 3,33 para as do Nível 2 e 3,74 para as do Novo Mercado. Com relação à variabilidade das notas, verificou-se comportamento semelhante entre as empresas do mercado tradicional e as do Nível 1, com desvios-padrão de 1,564 e 1,418, respectivamente. As companhias dos demais segmentos 
registraram menor variabilidade nas notas, com desvio-padrão 1,047 para as do Nível 2 e 1,197 para as do Novo Mercado. A nota 2 foi a moda (mais frequente) para as empresas do mercado tradicional, sendo 3 a moda para as dos Níveis 1 e 2 e a nota 4 a moda para as do Novo Mercado.

Tabela 5 - Estatística descritiva das notas de divulgação por segmento da BM\&FBovespa

\begin{tabular}{c|c|c|c|c|c|c}
\hline \multirow{2}{*}{ Segmento } & \multicolumn{7}{|c}{ Nota de Divulgação } \\
\cline { 2 - 7 } & Média & Mediana & Moda & Desvio Padrão & Mínimo & Máximo \\
\hline MT & 2,41 & 2 & 2 & 1,564 & 0 & 5 \\
\hline N1 & 3,37 & 3 & 3 & 1,418 & 1 & 6 \\
\hline N2 & 3,33 & 3 & 3 & 1,047 & 1 & 5 \\
\hline NM & 3,74 & 4 & 4 & 1,197 & 0 & 6 \\
\hline
\end{tabular}

\subsection{Análise das variações entre as médias das Notas de Divulgação}

As análises demonstram que as empresas dos segmentos diferenciados da BM\&FBovespa alcançaram Notas de Divulgação diferentes e superiores àquelas registradas pelas companhias do mercado tradicional. Contudo, para a confirmação da hipótese conceitual que norteia a pesquisa, é preciso investigar se há diferenças estatisticamente significantes entre as médias das Notas de Divulgação das empresas listadas nos níveis diferenciados de governança corporativa da BM\&FBovespa e das companhias do seu segmento tradicional.

Nesse sentido, realizou-se, inicialmente, teste não paramétrico utilizando-se o modelo de Mann-Whitney numa comparação das notas das empresas do mercado tradicional com as notas das demais companhias. Conforme ressaltado no tópico Metodologia, não foi utilizado o teste $t$ (Student) porque a aplicação do teste Kolmogorov-Smirnov revelou que os dados das amostras não apresentam distribuição normal.

O teste evidenciou que as médias dos grupos são significativamente diferentes, ao nível de significância de 5\%, confirmando-se a hipótese de que as Notas de Divulgação das empresas dos níveis diferenciados de governança corporativa são superiores às Notas de Divulgação das empresas do mercado tradicional.

Em seguida, investigou-se a significância da variação entre as médias, confrontando-se apenas as empresas do mercado tradicional com as do Nível 1. Mais uma vez realizou-se o teste de Mann-Whitney, optando-se pela significância exata, uma vez que se trabalhou com uma amostra de 27 empresas para o Nível 1. O teste revelou que as médias dos grupos também são significativamente diferentes, ao nível de significância de 5\%, confirmando-se a hipótese de que as Notas de Divulgação das empresas do Nível 1 são superiores às Notas de Divulgação das empresas do mercado tradicional.

O modelo de Mann-Whitney também foi aplicado para investigar se eram estatisticamente significativas as diferenças entre as médias das notas: a) das empresas do mercado tradicional e as das empresas do Nível 2; b) das empresas do mercado tradicional e as das empresas do Novo Mercado. Os testes estatísticos rejeitaram as hipóteses de igualdade entre as médias, ao nível de significância de $5 \%$, confirmando-se então as hipóteses:

a) As Notas de Divulgação das empresas do Nível 2 são superiores às Notas de Divulgação das empresas do mercado tradicional;

b) As Notas de Divulgação das empresas do Novo Mercado são superiores às Notas de Divulgação das empresas do mercado tradicional.

Os resultados dos testes estatísticos de diferenças entre as médias são apresentados na Tabela 6. 
Tabela 6 - Resultados dos testes de diferenças entre médias das Notas de Divulgação dos segmentos da BM\&FBovespa

\begin{tabular}{c|c|c|c|c}
\hline & NDGC $x$ MT & NM $x$ MT & N1 x MT & N2 x MT \\
\hline Z & $-6,891$ & $-6,708$ & $-2,900$ & $-2,308$ \\
\hline Mann-Whitney U & 7570 & 4824 & 1778 & 968 \\
\hline Significância & 0,000 & 0,000 & 0,002 & 0,010 \\
\hline
\end{tabular}

\section{CONCLUSÕES}

A presente pesquisa teve como principal objetivo investigar o grau de cumprimento das orientações de divulgação definidas no CPC 13 por parte das companhias listadas na BM\&FBovespa e verificar se existiu uma maior observância pelas empresas do NDGC.

Assim, de um total de 433 empresas, foram analisadas as notas explicativas às Demonstrações Financeiras Padronizadas de 2008 referentes a 334 delas, sendo 199 do mercado tradicional, 93 do Novo Mercado, 27 do Nível 1 e 15 do Nível 2.

Para a amostra como um todo, a variável operacional, "Nota de Divulgação", concebida com o objetivo de possibilitar a mensuração do grau de cumprimento das práticas de evidenciação, alcançou média 2,9, quando o escore máximo era 6 . Assim, numa escala de 0 a 10 , o grupo alcançou média inferior a 5, indicando um baixo grau de cumprimento das orientações de divulgação do CPC 13 pelas companhias abertas.

A média das notas das empresas do mercado tradicional situou-se em 2,41, enquanto as dos segmentos diferenciados assinalaram escores superiores a 3: 3,37 para as empresas do Nível 1; 3,33 para as do Nível 2 e 3,74 para as do Novo Mercado. Dessa forma, o estudo revela que nas empresas dos níveis diferenciados de governança corporativa da BM\&FBovespa registrou-se maior proporção no tocante à observância das práticas de divulgação.

Com o objetivo de investigar a significância das diferenças entre as Notas de Divulgação dos grupos de empresas, foram realizados testes não paramétricos utilizando-se o modelo de MannWhitney numa comparação das notas das empresas do mercado tradicional com as notas das demais companhias. Os testes indicaram que as diferenças entre as médias dos grupos eram estatisticamente significantes, ao nível de 5\%.

Assim, confirma-se a hipótese do trabalho que nem todas as companhias observaram as orientações de divulgação do CPC 13 e nas empresas listadas nos NDGC da BM\&FBovespa foi maior a observância do normativo quando comparadas com as do segmento tradicional.

Os resultados do estudo corroboram pesquisas anteriores que indicam haver uma ligação entre o nível de disclosure e as características de governança apontando que empresas com melhor estrutura de governança teriam maior nível de disclosure apresentando maior compromisso com a transparência e a prestação de informações fidedignas (BOTOSAN, 1997; CHEN; JAGGI, 2000; ENG; MAK, 2003; FORKER, 1992; HO; WONG, 2001; LANZANA, 2004).

A pesquisa indica uma associação positiva entre o nível de disclosure e a adesão a um dos níveis diferenciados de governança corporativa da BM\&FBovespa reforçando os achados de Pereira et al (2008) e de Costa, Goldner e Galdi (2007).

Sugere-se, por fim, que estudos investiguem o cumprimento das orientações de divulgação definidas nos demais pronunciamentos do CPC, em virtude da relevância do disclosure para o mercado de capitais brasileiro. 


\section{REFERÊNCIAS}

AGUIAR, A. B.; CORRAR, L. J.; BATISTELLA, F. D. Adoção de práticas de governança corporativa e o comportamento das ações na Bovespa: evidências empíricas. Revista de Administração da USP (RAUSP), São Paulo, v. 39, n. 4, p. 338-347, out./nov./dez. 2004.

BERLE, A. A.; MEANS, G. C. The modern corporation and private property. Ninth printing. New Brunswick, New Jersey (U.S.A.): Transaction Publishers, 2007. Originally published in 1932 by Harcourt, Brace \& World.

BOTOSAN, C. A. Disclosure level and the cost of equity capital. The Accounting Review 72 (3), p. 323-349, 1997.

CAMARGOS, Marcos Antônio de; HELAL, Diogo Henrique. Remuneração executiva, desempenho econômico-financeiro e a estrutura de governança corporativa de empresas brasileiras. In: ENCONTRO ANUAL DA ASSOCIAÇÃO NACIONAL DOS PROGRAMAS DE PÓS-GRADUAÇÃO EM ADMINISTRAÇÃO-ENANPAD-ENANPAD, 31., 2007. Anais... Rio de Janeiro: ANPAD, 2007.

CHEN, J.; JAGGI, B. Association between independent non-executive directors, family control and financial disclosures in Hong Kong. Journal of Accounting and Public Policy 19, p. 285-310, 2000.

CHRISTENSEN, Hans B.; LEE, Edward; WALKER, Martin. Cross-sectional variation in the economic consequences of international accounting harmonization: the case of mandatory IFRS adoption in the UK. The International Journal of Accounting, Unites States, v. 42(4), p. 341-379, December 2007.

CORTESI, Alessandro; MONTANI, Elena; TETTAMANZI, Patrizia. IAS/IFRS adoption by italian listed companies: first empirical evidences. International Review of Business Research Papers, Australia, v. 5, n. 4, p. 388 -398, June 2009.

COMITÊ DE PRONUNCIAMENTOS CONTÁBEIS. Pronunciamento Técnico CPC 13 - Adoção Inicial da Lei $n^{\circ}$ 11.638/07 e da Medida Provisória no 449/08. Disponível em: <http://www.cpc.org.br/ mostraOrientacao.php?id=27> Acesso em: 25 mar e 10 abr. 2009.

COSTA, Fábio Moraes da; GOLDNER, Fábio; GALDI, Fernando Caio. Análise dos fatores que influenciam no disclosure dos maiores bancos brasileiros. In: CONGRESSO USP DE CONTABILIDADE E CONTROLADORIA, 7., 2007, São Paulo. Anais... São Paulo: USP, 2007. CD-ROM.

DANCEY, Christine P.; REIDY, John. Estatística sem matemática para psicologia: usando SPSS para Windows. Porto Alegre: Artmed, 2006.

ENG, L. L.; MAK, Y. T. Corporate governance and voluntary disclosure. Journal of Accounting and Public Policy 22, p. 325-345, 2003.

FORKER, J. J. Corporate governance and disclosure quality. Accounting and Business Research 22 (86), p. 111-124, 1992.

FINANCIAL STABILITY FORUM. Disponível em: <http:/www.fsforum.org/about/history.htm>. Acesso em: 10 abr. 2009. 
GERON, Cecíclia Moraes Santostaso. Evolução das práticas contábeis no Brasil nos últimos 30 anos: da Lei 6.404/76 à Lei 11.638/07. 2008. Dissertação (Mestrado em Controladoria e Contabilidade) - Departamento de Contabilidade e Atuária da Universidade de São Paulo, São Paulo.

HO, S. S.; WONG, K. S. A study of the relationship between corporate governance structures and the extent of voluntary disclosure. Journal of International Accounting, Auditing and Taxation 10, p. 139-156, 2001.

IBGC (Instituto Brasileiro de Governança Corporativa). Código brasileiro das melhores práticas de governança corporativa. 3. ed. São Paulo: IBGC, 2009. Disponível em: < http://www.ibgc.org.br/home. asp>. Acesso em: 5 dez .2009.

IASB. IFRSs around the world. Disponível em: $<$ http://www.iasb.org/About+Us/About+the+IASB/ IFRSs+around +the+world.htm>. Acesso em: 20 ago. 2009.

LANZANA, A. P. Relação entre disclosure e governança corporativa das empresas brasileiras. 2004. 161 f. Dissertação (Mestrado em Controladoria e Contabilidade) - Departamento de Contabilidade e Atuária da Universidade de São Paulo, São Paulo.

LEITE, Joubert da S. J. Normas contábeis internacionais: uma visão para o futuro. Cadernos da Faceca, Campinas, v. 11, n. 1, p. 51-65, jan./jun. 2002.

LIMA, Gerlando Augusto Sampaio Franco de. Utilização da teoria da divulgação para avaliação da relação do nível de disclosure com o custo da dívida das empresas brasileiras. 2007. 118f. Tese (Doutorado em Ciências Contábeis) - Faculdade de Economia, Administração e Contabilidade, Universidade de São Paulo, São Paulo, 2007.

LOPES, Alexsandro Broedel A teoria dos contratos, governança corporativa e Contabilidade. In: IUDÍCIBUS, Sérgio; LOPES, Alexsandro Broedel. Teoria avançada da Contabilidade. São Paulo: Editora Atlas, 2004.

LOPES, Alexsandro Broedel; MARTINS, Eliseu. Teoria da Contabilidade: uma nova abordagem. São Paulo: Atlas, 2005.

MELLO, Rita de Cássia; CIA, Joanília Neide de Sales. Análise da harmonização contábil: uma comparação entre indicadores calculados pelo BR GAAP e US GAAP dos bancos com ADR listados na NYSE. In: CONGRESSO USP DE CONTROLADORIA E CONTABILIDADE, Anais... 7., São Paulo, FEA/USP. 2007.

MURCIA, Fernando Dal-Ri. Fatores determinantes do nível de disclosure voluntário de companhias abertas no Brasil. 2009. 182f. Tese (Doutorado em Ciências Contábeis) - Faculdade de Economia, Administração e Contabilidade, Universidade de São Paulo, São Paulo, 2009.

NIYAMA, Jorge Katsumi. Contabilidade internacional. São Paulo: Atlas, 2005.

OECD. The OECD principles of corporate governance. Disponível em: <http://www.oecd.org>. Acesso em: abr. 2009. 


\section{repec}

PEREIRA, Dimmitre Morant Vieira Gonçalves et al. Um estudo sobre a relação entre o lucro contábil e o disclosure das companhias abertas do setor de materiais básicos: evidências empíricas no mercado brasileiro de capitais. In: ENCONTRO DA ASSOCIAÇÃO NACIONAL DO PROGRAMAS DE PÓS GRADUAÇÃO EM CIÊNCIAS CONTÁBEIS, 2., 2008, Salvador. Anais... São Paulo: Anpcont, 2008. CD-ROM.

SUPERINTENDENTE SUBSTITUTO DA SUPERINTENDÊNCIA DE SEGUROS PRIVADOS. Circular n. 357, de 26 de dezembro de 2007. Disponível em: <www.cpc.org.br/pdf/circ357_susep. pdf> Acesso em: 1 ago. 2009.

SZUSTER, Flávia Rechtman, SZUSTER, Natan. O Brasil rumo à convergência internacional da Contabilidade: o caso Gerdau S.A. In: ENCONTRO ANUAL DA ASSOCIAÇÃO NACIONAL DOS PROGRAMAS DE PÓS-GRADUAÇÃO EM ADMINISTRAÇÃO-ENANPAD-ENANPAD, 32., 2008. Anais... Rio de Janeiro: ANPAD, 2008.

THE WORLD BANK. Reports on the observance of standards and codes - ROSC. Disponível em: <http:/www.worldbank.org/ifa/rosc>. Acesso em: 10 abr. 2009.

YAMAMOTO, Marina Mitiyo; SALOTTI, Bruno Meirelles. Informação contábil: estudos sobre a sua divulgação no mercado de capitais. São Paulo: Atlas, 2006. 